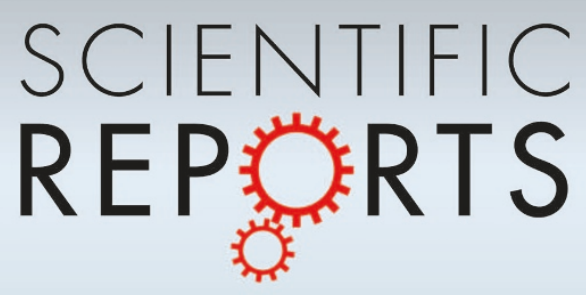

OPEN

SUBJECT AREAS:

TISSUE ENGINEERING

IMPLANTS

NANOFABRICATION AND NANOPATTERNING

Received

25 November 2013

Accepted

31 March 2014

Published

16 April 2014

Correspondence and requests for materials should be addressed to C.J.S. (shuai@csu.edu.

cn)

\section{Enhancement mechanisms of graphene in nano-58S bioactive glass scaffold: mechanical and biological performance}

\author{
Chengde Gao', Tingting Liu', Cijun Shuai ${ }^{1,2}$ \& Shuping Peng ${ }^{3,4}$
}

\author{
'State Key Laboratory of High Performance Complex Manufacturing, Central South University, Changsha 410083, P. R. China, \\ ${ }^{2}$ Department of Regenerative Medicine \& Cell Biology, Medical University of South Carolina, Charleston, SC 29425, USA, ${ }^{3}$ Cancer \\ Research Institute, Central South University, Changsha 410078, P. R. China, ${ }^{4}$ Department of Obstetrics, Gynecology and \\ Reproductive Sciences, Yale University School of Medicine, New Haven, CT 06520, USA.
}

Graphene is a novel material and currently popular as an enabler for the next-generation nanocomposites. Here, we report the use of graphene to improve the mechanical properties of nano-58S bioactive glass for bone repair and regeneration. And the composite scaffolds were fabricated by a homemade selective laser sintering system. Qualitative and quantitative analysis demonstrated the successful incorporation of graphene into the scaffold without obvious structural damage and weight loss. The optimum compressive strength and fracture toughness reached $48.65 \pm 3.19 \mathrm{MPa}$ and $1.94 \pm 0.10 \mathrm{MPa} \cdot \mathrm{m}^{1 / 2}$ with graphene content of $0.5 \mathrm{wt} \%$, indicating significant improvements by $105 \%$ and $38 \%$ respectively. The mechanisms of pull-out, crack bridging, crack deflection and crack tip shielding were found to be responsible for the mechanical enhancement. Simulated body fluid and cell culture tests indicated favorable bioactivity and biocompatibility of the composite scaffold. The results suggest a great potential of graphene/nano-58S composite scaffold for bone tissue engineering applications.
$58 \mathrm{~S}$ bioactive glass (58S) $\left(58 \% \mathrm{SiO}_{2}, 33 \% \mathrm{CaO}\right.$ and $9 \% \mathrm{P}_{2} \mathrm{O}_{5}$, based on mol\%) has received special attention as scaffold material owing to its good biodegradability, excellent bioactivity and bonebonding ability ${ }^{1,2}$. It reacts with physiological fluids to form direct bonds to bone tissue in the early time after implantation without toxicity, inflammation and foreign-body response ${ }^{3}$. The fast surface reactions in vivo lead to rapid ionic dissolution and formation of hydroxyl-carbonated apatite (HCA) layer ${ }^{4}$. The release of soluble $\mathrm{Si}, \mathrm{Ca}$, and $\mathrm{P}$ ions can activate gene expression and stimulate osteoblast proliferation for rapid bone formation ${ }^{5}$. Moreover, $58 \mathrm{~S}$ in nano scale (nano-58S) exhibits better bioactivity in terms of cell growth, osteogenic differentiation and HCA formation ${ }^{6}$. The major hurdles of $58 \mathrm{~S}$ are intrinsic brittleness, low fracture toughness and crack resistance to sustain the loads transmitted from surrounding bone tissue ${ }^{7}$, which is considered to be one of the main requirements of scaffolds during the period of new bone formation. Thus, there has been a strong impetus to improve the mechanical properties of $58 \mathrm{~S}$ scaffold in the past years.

Current attempts focused on improving the mechanical properties of $58 \mathrm{~S}$ by incorporating second phase reinforcements including polymers and metallic oxides. O'Shea et al. developed a poly(lactic-co-glycolic acid) (PLGA)-coated 58S scaffold. The addition of PLGA coating improved the compressive strength of $58 \mathrm{~S}$ scaffold to $0.25 \mathrm{MPa}$, which was twice that of uncoated $58 \mathrm{~S}$ scaffold $(0.12 \mathrm{MPa})$ but still lies toward the lower limit of cancellous bone ${ }^{8}$. Increasing efforts were also devoted to improve the mechanical properties by surface modification using organic molecular, which promoted the dispersion of $58 \mathrm{~S}$ particles in the composites ${ }^{9,10}$. Nevertheless, this method was also accompanied by a weakened capability for calcium precipitation ${ }^{11}$. So far, few of these scaffolds fulfill both the mechanical and biological requirements for load bearing applications.

Graphene possesses a unique two-dimensional structure with single-atom thickness and extensive conjugation, which endowed it with excellent mechanical, electrical and thermal properties ${ }^{12}$. These exceptional properties make graphene a key enabler for the next-generation nanocomposites ${ }^{13}$. Moreover, it is far superior to other known reinforcements in transferring their mechanical properties to host material. Recent findings demonstrated no adverse effect of graphene incorporation on the microenvironment in vivo ${ }^{14}$. The combination of promising biocompatibility and outstanding mechanical properties indicate the potential application of graphene as reinforcing phase in $58 \mathrm{~S}$ bone scaffold. However, till now researches have mainly focused on graphene/polymer composites and studies on graphene/ceramic composites are relatively limited. It is attributed to the greater 
difficulties in the dispersion and incorporation of graphene in ceramic-based composites, which require the employment of longtime high temperature and/or pressure during conventional consolidation process ${ }^{15}$. Thus, there is an urgent need for suitable processing technique to incorporate graphene in ceramic-based composites with minimum or no structural damage to graphene.

Selective laser sintering (SLS) has emerged as a promising technique to consolidate three dimensional (3D) scaffolds through layer-by-layer deposition process ${ }^{16}$. The duration of laser beam at individual particle is typically between 0.5 and $25 \mathrm{~ms}$, enabling a much shorter processing time of SLS compared with conventional sintering techniques ${ }^{17}$. This is expected to avoid oxidative damage to graphene and inhibit devitrification of $58 \mathrm{~S}$ during the sintering process. Furthermore, SLS is qualified for fabricating scaffolds with customized shape and porous structure in order to match the specific requirements of individual patients ${ }^{18}$. Up to now, there is a dearth of literature in the use of graphene to improve the mechanical properties of nano-58S. The SLS fabrication of graphene/nano-58S composite scaffold and corresponding enhancement mechanism remain to be systematically explored.

In this study, nano-58S was combined with graphene in order to enhance its poor mechanical properties for bone tissue engineering applications. 3D porous composite scaffolds of graphene/nano-58S were fabricated using SLS technique. The microstructure and chemical composition were studied by scanning electron microscopy/ energy dispersive spectroscopy (SEM/EDS), Fourier transform infrared spectroscopy (FTIR), X-ray diffraction (XRD) and field emission transmission electron microscopy (FE-TEM). The graphene in the scaffold was analyzed using Raman spectroscopy and thermogravimetric analysis (TGA). The compressive strength and fracture toughness were investigated by compression test and indentation method. The enhancement mechanism was discussed based on the test results. The biocompatibility and bioactivity were assessed after immersion in simulated body fluid (SBF) and by in-vitro cell culture using human osteoblast-like cells (MG-63).

\section{Results}

Good dispersibility of graphene in solvent can possess uniform distribution in matrix, which helps to maintain uniform properties throughout the composite. The dispersion states of the starting powders in NMP were shown in Fig. 1a. It can be seen that graphene suspension exhibited visually homogeneous and stable solution with
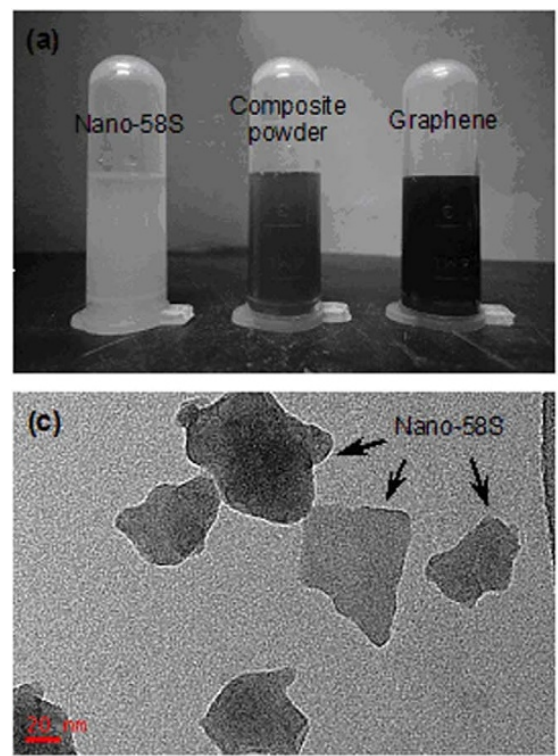

black color. The forces keeping graphene dispersed in NMP arose from the hydrogen bonds formed between graphene and the solvent $^{19}$. TEM image showed many ripples and wrinkles on the asreceived graphene surface (Fig. 1b), which was benefit for protein adsorption and cell adhesion ${ }^{20,21}$. Besides, nano- $58 \mathrm{~S}$ powder was also well dispersed in the solvent and yielded a white suspension. The powder consisted of irregular particles with a size of $30-60 \mathrm{~nm}$ (Fig. 1c). After mixing with graphene suspension and ultrasonication, a composite solution was obtained with dark gray color. And nano-58S particles were found to uniformly and intimately anchor on the graphene surface, as can be seen in Fig. 1d.

Raman analysis was carried out to investigate the structure changes of graphene after the sintering process (Fig. 2). The spectrum of as-received graphene was dominated by a $D$ peak at $1359 \mathrm{~cm}^{-1}$ and a $G$ peak at $1586 \mathrm{~cm}^{-1}$ (Fig. 2a). The $G$ peak referred to $\mathrm{C}-\mathrm{C}$ stretching vibration while the $\mathrm{D}$ peak originated from the structural disorder and defects in graphene ${ }^{22}$. A broad band was also observed around $2915 \mathrm{~cm}^{-1}$ corresponding to $2 \mathrm{D}, \mathrm{D}+\mathrm{G}$ and $2 \mathrm{D}^{\prime}$ peaks $^{23}$. No peaks were found in the spectral region from 1200 to $3200 \mathrm{~cm}^{-1}$ for $58 \mathrm{~S}-0$ (Fig. 2b). The aforementioned peaks were presented in the spectra of sintered samples with graphene, confirming the survival of graphene after SLS process. In comparison with the asreceived graphene, there was only a slight increase of the intensity ratio of $\mathrm{D}$ peak to $\mathrm{G}$ peak $\left(\mathrm{I}_{\mathrm{D}} / \mathrm{I}_{\mathrm{G}}\right)$ for graphene-containing samples (Figs. 2c-f), indicating a higher degree of disorder in the graphene lattice ${ }^{24}$. The Raman results demonstrated the successful incorporation of graphene into nano-58S scaffold by SLS without obvious structural damage.

The TGA curves of as-received graphene and sintered samples were obtained (Fig. 3) in order to estimate the weight retention of graphene after the SLS process. The curves showed a weight loss below $200^{\circ} \mathrm{C}$, owing to the evaporation of adsorbed water ${ }^{25}$. A weight loss (14.1 wt\%) occurred between 200 and $500^{\circ} \mathrm{C}$ in the curve of asreceived graphene (Fig. 3a), which can be assigned to the oxidation of amorphous carbon ${ }^{26}$. A significant weight loss (70 wt\%) was noticed in the range of $500-675^{\circ} \mathrm{C}$, corresponding to the complete combustion of the carbon skeleton of graphene ${ }^{27}$. In contrast, no obvious weight loss $(0.009 \mathrm{wt} \%)$ was found in this temperature range for 58S0 (Fig. 3b). This indicated that the weight loss in the temperature range of $500-675^{\circ} \mathrm{C}$ corresponded to the graphene content in the sintered samples. As can be seen in Figs. $3 \mathrm{c}-\mathrm{f}$, the weight losses in this temperature range were about $0.11,0.48,0.99$ and $1.53 \mathrm{wt} \%$, which
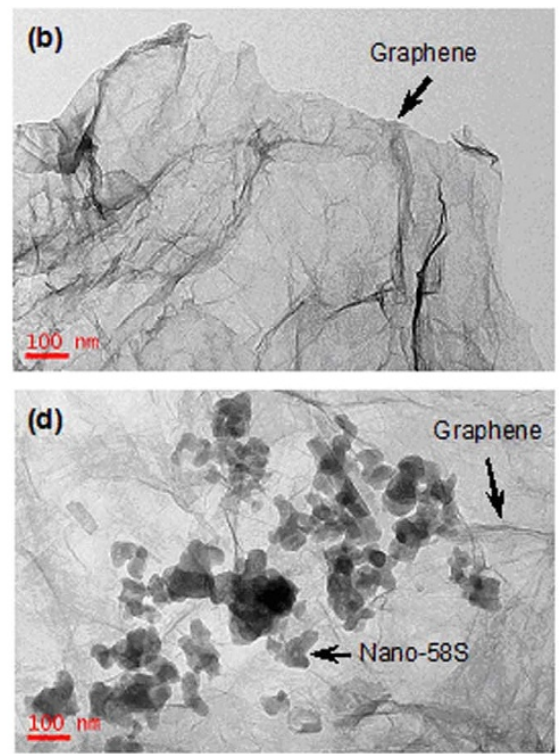

Figure 1 Material preparation. (a) dispersion of the starting powders in NMP. TEM images of (b) as-received graphene, (c) as-received nano-58S powder and (d) graphene/nano-58S composite powder. 


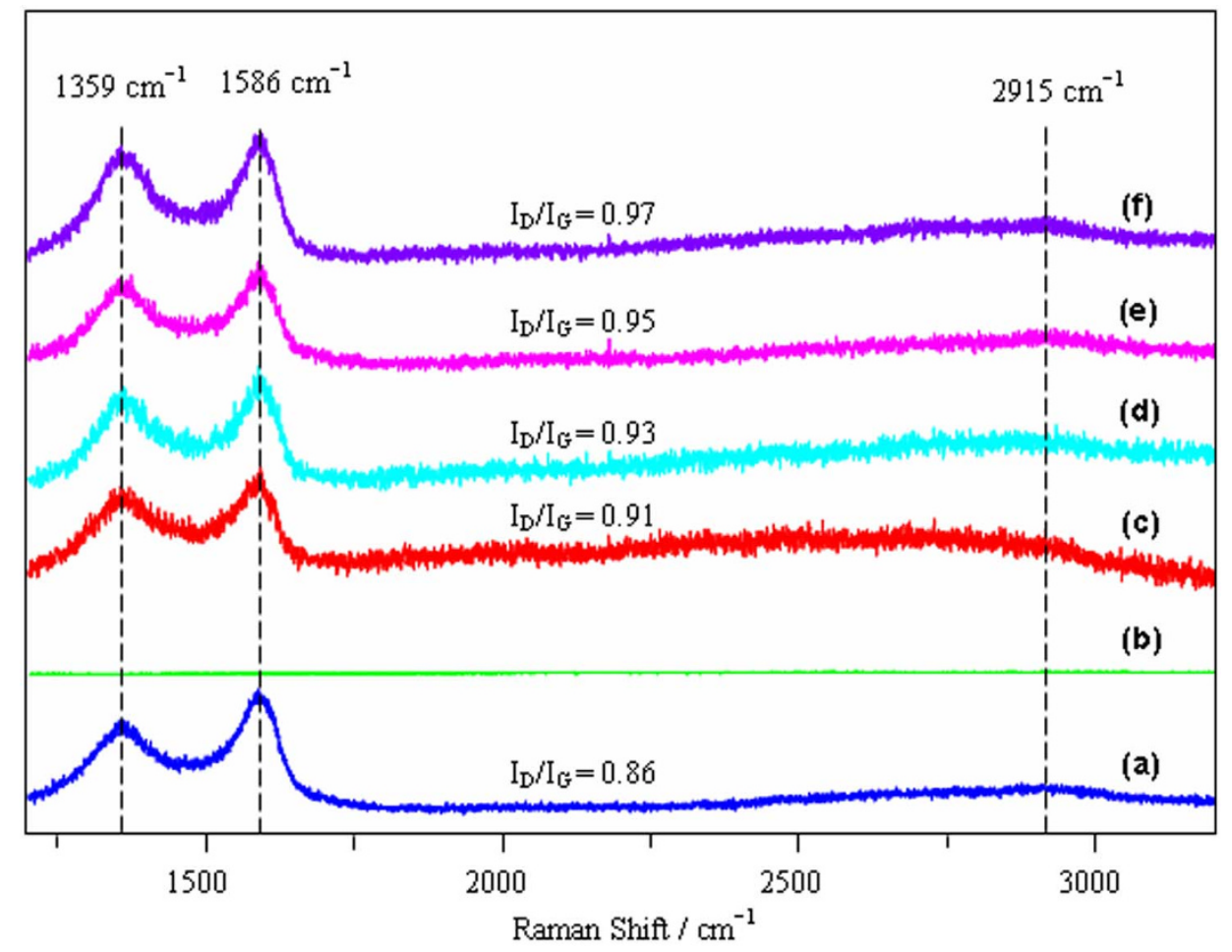

Figure $2 \mid$ Raman spectra. (a) as-received graphene. (b) 58S-0. (c) 58S-0.1. (d) 58S-0.5. (e) 58S-1. (f) 58S-1.5.

represented the amount of graphene in 58S-0.1, 58S-0.5, 58S- 1 and 58S- 1.5 respectively. As the temperature increased above $675^{\circ} \mathrm{C}$, the weight loss slowed down and plateau formed in the TGA curves. The TGA results demonstrated little weight loss of graphene after the SLS process in nitrogen atmosphere.

The FT-IR spectra of the starting powders and sintered samples were shown in Fig. 4. The spectrum of as-received nano-58S powder (Fig. 4a) was dominated by a strong absorption band in the region $900-1200 \mathrm{~cm}^{-1}$, which was a combination of $\mathrm{Si}-\mathrm{O}-\mathrm{Si}$ stretching and $\mathrm{P}-\mathrm{O}$ stretching vibrations in the glass network ${ }^{28}$. And the absorption peak at $466 \mathrm{~cm}^{-1}$ was ascribed to the bending vibration of $\mathrm{Si}-\mathrm{O}-\mathrm{Si}^{29}$. The small band appeared in the vicinity of $1498 \mathrm{~cm}^{-1}$ was the typical absorption band of carbonates as a result of the admission of water and $\mathrm{CO}_{2}$ on nano-58S powder ${ }^{30}$. The spectrum of as-received graphene (Fig. 4b) exhibited an absorption band at $1558 \mathrm{~cm}^{-1}$, associating with the $\mathrm{C}=\mathrm{C}$ skeletal vibration ${ }^{31}$. The peak for $\mathrm{C}=\mathrm{C}$ stretching vibration ${ }^{32}$ was observed at $1630 \mathrm{~cm}^{-1}$. The dispersive band located around $1069 \mathrm{~cm}^{-1}$ corresponded to the $\mathrm{C}-\mathrm{O}$ stretching vibration in the reduced graphene ${ }^{33,34}$. The spectrum of composite powder was similar to that of nano-58S powder due to the low content of graphene (Fig. 4c). Absorption peak at $940 \mathrm{~cm}^{-1}$ was observed in the spectrum of $58 \mathrm{~S}-0$ (Fig. $4 \mathrm{~d}$ ), which can be attributed to the formation of $\mathrm{SiO}$ groups with non-bridging oxygens ${ }^{35}$. For the sintered samples with graphene (Figs. 4e-h), a double peak that arose from the bending vibration of $\mathrm{P}-\mathrm{O}$ appeared at 567 and $605 \mathrm{~cm}^{-1}$, indicating the formation of crystalline phosphate in the glasses ${ }^{36}$.

The XRD patterns of the starting powders and sintered samples were shown in Fig. 5. It can be seen that the as-received nano-58S powder was amorphous, and no diffraction peaks were observed except for a broad band of $2 \theta$ between $26^{\circ}$ and $32^{\circ}$ (Fig. 5a). There was only a broad band at about $24^{\circ}$ in the pattern of as-received graphene (Fig. 5b), which was attributed to the irregular arrays of atoms in three dimensions ${ }^{37}$. After mixing with nano-58S powder, no trace of graphene was detected by XRD analysis because of its low amount in the composite powder (Fig. 5c). There was a similar XRD pattern among the sintered samples with and without graphene addition (Figs. 5 d-h). Diffraction peaks of wollastonite $\left(\mathrm{CaSiO}_{3}\right)$ were identified at about $27.5^{\circ}, 31.7^{\circ}$ and $45.7^{\circ}$ in all the sintered samples ${ }^{38}$, indicating partial crystallization occurred in the nano58S. The addition of graphene had no influence on the phase composition of sintered samples, since no obvious difference were found among the patterns with different graphene contents. Besides, the crystalline phosphate found in the FT-IR results were absent in the XRD patterns, which might be attributed to the trace amount of crystalline phosphate and insufficient detection limit of XRD method $^{39}$.

The mechanical properties of sintered samples were obtained by compressive tests and indentation technique, as shown in Fig. 6. It can be seen that the compressive strength firstly increased from 23.66 $\pm 3.90 \mathrm{MPa}$ for $58 \mathrm{~S}-0$ to $48.65 \pm 3.19 \mathrm{MPa}$ for $58 \mathrm{~S}-0.5$, followed by a decrease to $44.19 \pm 4.27$ and $37.92 \pm 3.84 \mathrm{MPa}$ with increasing graphene content up to 1.0 or $1.5 \mathrm{wt} \%$. The fracture toughness of sintered samples increased with the addition of graphene from 0 to $0.5 \mathrm{wt} \%$ and then diminished as graphene content reached 1.0 or $1.5 \mathrm{wt} \%$. Incorporation of $0.5 \mathrm{wt} \%$ graphene improved the fracture toughness of nano-58S by $38 \%$ from $1.41 \pm 0.07$ to $1.94 \pm$ $0.10 \mathrm{MPa} \cdot \mathrm{m}^{1 / 2}$. It was clear from the data that the $58 \mathrm{~S}-0.5$ displayed the highest compressive strength and fracture toughness among the samples tested. While the diminished enhancements of 58S-1 and 58S-1.5 might be attributed to the degradation in dispersion of graphene at high content.

Apart from the mechanical properties, bioactivity and biocompatibility of $58 \mathrm{~S}-0.5$ were studied by SBF and cell culture tests. SEM image revealed that the surface of 58S-0.5 scaffold was covered by a thick and well formed HCA layer after immersion in SBF for 7 days (Fig. 7a). Precipitated granules were found to distribute homogeneously on the surface in the magnified SEM image (Fig. 7b). EDS analysis of the precipitated granules revealed a mean molar $\mathrm{Ca} / \mathrm{P}$ ratio of about 1.69 (Fig. 7c). XRD analysis (Fig. 7d) indicated that the diffraction peaks of (002) and (211) surfaces of $\mathrm{HCA}^{40}$ were superposed on that of $\mathrm{CaSiO}_{3}$ at $2 \theta$ of $25.8^{\circ}$ and $31.7^{\circ}$. The other peaks of HCA were observed at $2 \theta$ of $39^{\circ}$ and $46^{\circ}$, corresponding to the (310) and (222) surfaces respectively ${ }^{41}$. The apatite layer on 58S-0.5 scaffold was further 

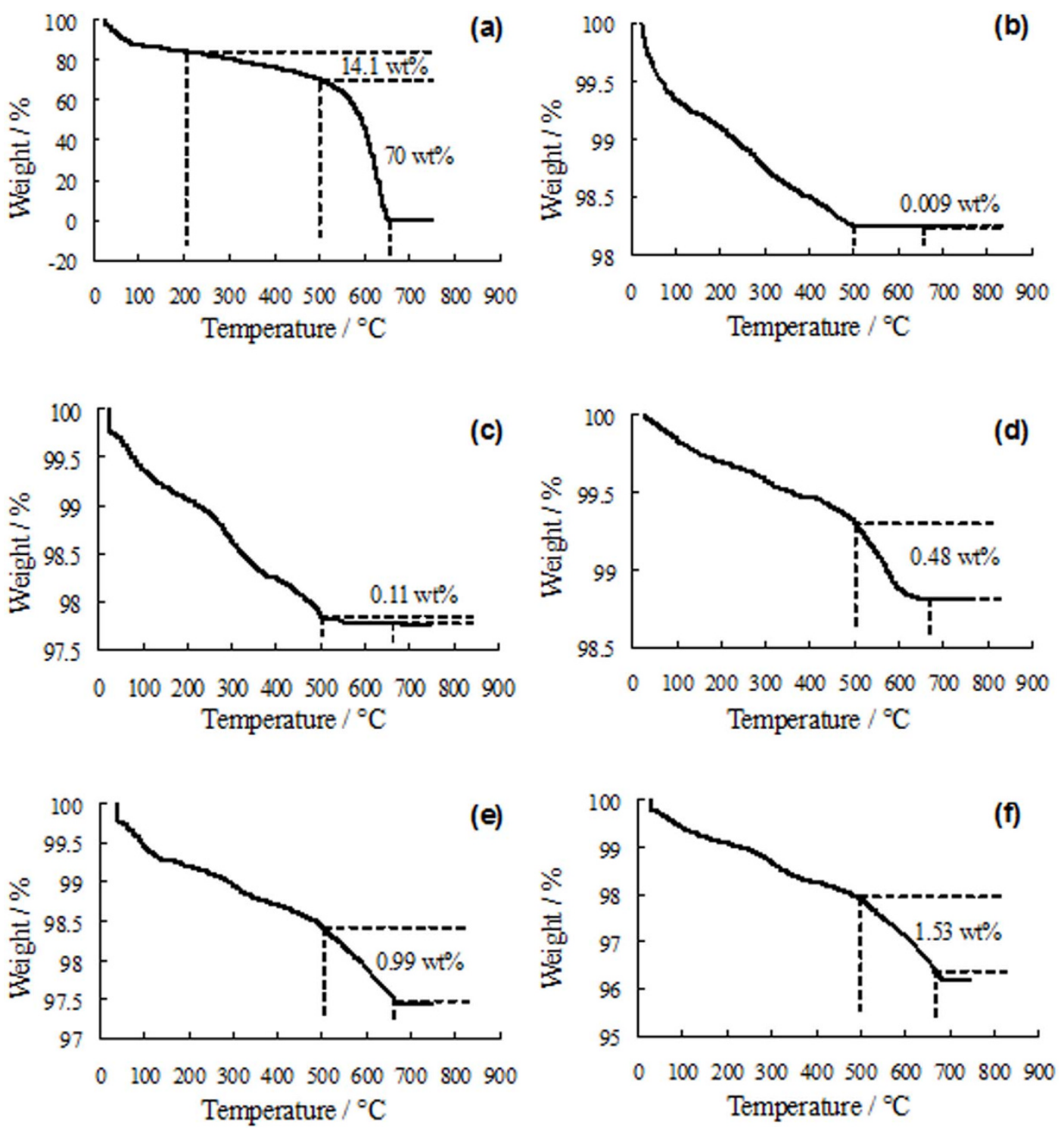

Figure 3 TGA curves. (a) as-received graphene. (b) 58S-0. (c) 58S-0.1. (d) 58S-0.5. (e) 58S-1. (f) 58S-1.5.

analyzed using FTIR and shown in Fig. 7e. The double peak corresponding to $\mathrm{P}-\mathrm{O}$ bending vibrations was observed at 558 and $605 \mathrm{~cm}^{-1}$ in the spectrum, while the $\mathrm{P}-\mathrm{O}$ stretching band was superposed on the $\mathrm{Si}-\mathrm{O}$ stretching band of $58 \mathrm{~S}$ at about $1082 \mathrm{~cm}^{-1}$. Well-defined carbonate bands were presented at 875 (C-O bending vibration) and $1420-1480 \mathrm{~cm}^{-1}$ (C-O stretching vibration $)^{42,43}$, indicating the incorporation of carbonate into the apatite layer. These findings further confirmed the formation of HCA layer on the surface of 58S- 0.5 scaffold after immersing in SBF. In vitro cell culture tests revealed that MG-63 cells colonized and grew favorably on 58S-0.5 scaffold after 7 days (Fig. 7f). MG63 cells showed a round shape with mineralised nodules and were anchored to the surface by elongated filopodia, suggesting a good cell biocompatibility of the scaffold.

A graphene/nano-58S composite scaffold was fabricated with the optimum graphene content $(0.5 \mathrm{wt} \%)$ at laser power of $7.5 \mathrm{~W}$, scan speed of $100 \mathrm{~mm} / \mathrm{min}$ and spot diameter of $1 \mathrm{~mm}$. The digital images of the scaffold (Figs. 8a-d) showed a 3D network of interconnected pores which were approximately $0.8 \mu \mathrm{m}$ in size and isotropic in their distribution. SEM image indicated good connections between pore walls (Fig. 8e). The high degree of porosity and pore interconnectivity are beneficial for vascularisation in vivo and rapid osteogenesis $^{44}$.

\section{Discussion}

The typical toughening mechanisms for graphene-based materials can be summarized as follows: (a) Crack bridging. Graphene bridges the two surfaces of crack and provides a closure stress to counteract the applied stress, delaying further propagation of the crack. (b) Pullout. Graphene is pulled out the matrix and slows down crack propagation by the interfacial friction between graphene and matrix. (c) Crack deflection. Crack deflects into a different plane when it encounters graphene, resulting in a tortuous path and more energy dissipation for crack propagation. (d) Crack tip shielding. The crack tip is restricted in the vicinity of graphene due to the insufficient energy required for interface debonding. The indentations and radial cracks were characterized by SEM to identify the mechanism responsible for the enhanced mechanical properties (Fig. 9). A representative microhardness indentation and induced radial cracks were prepared on the polished surface of 58S-0.5 (Fig. 9a). Magnified image in Fig. 9b showed the presence of graphene pull-out and crack bridging (labeled by white arrows) on the fracture line. Individual graphene bridged the gap between the crack surfaces, delaying the rupture of $58 \mathrm{~S}$ matrix. EDS analysis confirmed the toughening effect by graphene since a strong peak referred to carbon element was observed in the spectrum. The direct evidence of graphene pull-out and crack bridging were also observed in Fig. 9c. The 


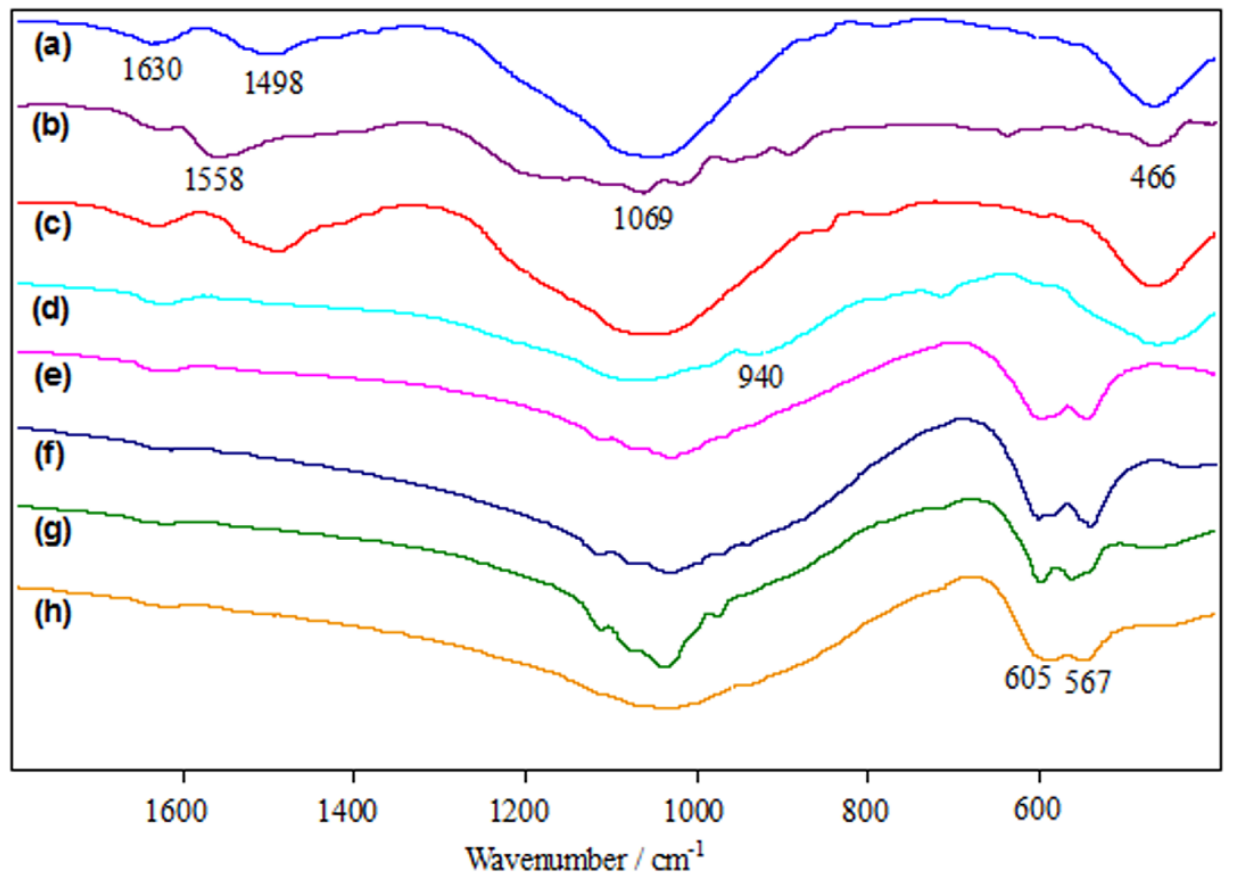

Figure 4 | FT-IR spectra. (a) as-received nano-58S powder. (b) as-received graphene. (c) composite powder. (d) 58S-0. (e) 58S-0.1. (f) 58S-0.5. (g) 58S-1. (h) $58 \mathrm{~S}-1.5$.

crack propagation was slowed down due to the loss of fracture energy by graphene pull-out. As a result, the reduced fracture energy was insufficient to pull out another graphene sheet and crack bridging formed in the propagation path. Characteristic crack deflections were visible in Fig. 9d and 9e. The crack firstly propagated in its own plane and then along graphene-58S interface when met with graphene, followed by the deflection to $58 \mathrm{~S}$ matrix. Such crack deflection occurred several times in the propagating path, which would force the crack to propagate along a very tortuous path to release stress. Crack tip shielding by graphene was observed in Fig. 9f, in which graphene effectively prevented the further propagation of crack tip. These results indicated that graphene was highly effective in suppressing crack propagation in 58S matrix. The mechanisms of graphene pull-out, crack bridging, crack deflection and crack tip shielding were responsible for the enhancement of compressive strength and fracture toughness.
The enhancement mechanisms associated with the morphological evidence were schematically depicted in Fig. 10. Once a matrix crack is initiated and propagates, load is transferred from the matrix to graphene due to the difference in elastic modulus. The wrinkled surface texture of graphene enabled efficient mechanical interlocking and load transfer with the matrix ${ }^{45}$. The toughening mechanism of crack bridging is shown in Fig. 10a where graphene bridges two crack surfaces. Graphene hampers the relative displacement between the opposite crack surfaces by alleviating the stress required for further crack propagation. The pull-out of graphene occurs when the shear stress at the interface exceeds the interfacial strength of graphene58 S (Fig. 10b). This mechanism requires high energy dissipation due to the high toughness and large surface area of graphene. The crack propagation can be effectively slowed down by additional resistance from the interfacial friction between graphene and 58S matrix. Fig. 10c demonstrates the toughening mechanism of crack

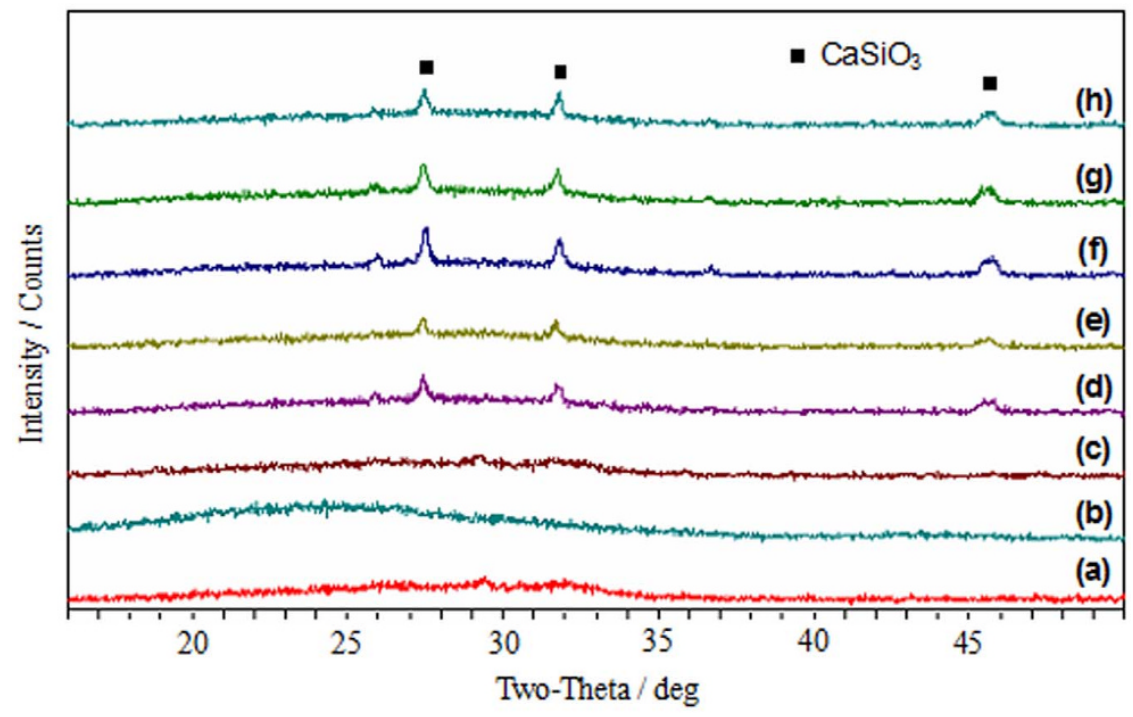

Figure $5 \mid$ XRD patterns. (a) as-received nano-58S powder. (b) as-received graphene. (c) composite powder. (d) 58S-0. (e) 58S-0.1. (f) 58S-0.5. (g) 58S-1. (h) $58 \mathrm{~S}-1.5$. 


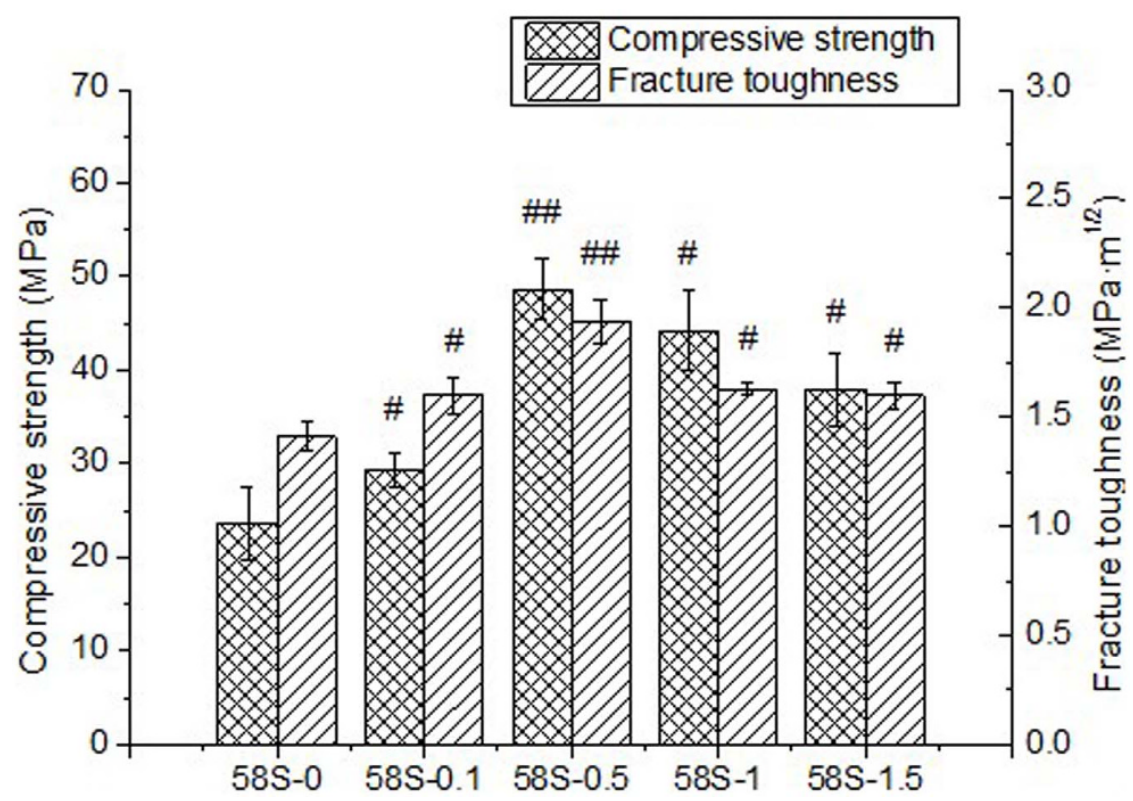

Figure 6 | Mechanical properties of sintered samples with different graphene contents. (\# $\mathrm{p}<0.05$, \#\# $\mathrm{p}<0.001$ compared with 58S-0).

deflection. A crack propagates firstly in $58 \mathrm{~S}$ matrix and then deflects into a different plane when it encounters graphene. More energy is required for the further propagation of crack, since the crack plane is no longer perpendicular to the axis of stress. Moreover, the deflection process generates a tortuous path for crack propagation, which allows much more energy dissipation. Crack deflection may be highly effective for graphene-based materials in virtue of the large specific surface area. As shown in Fig. 10d, the crack tip is restricted
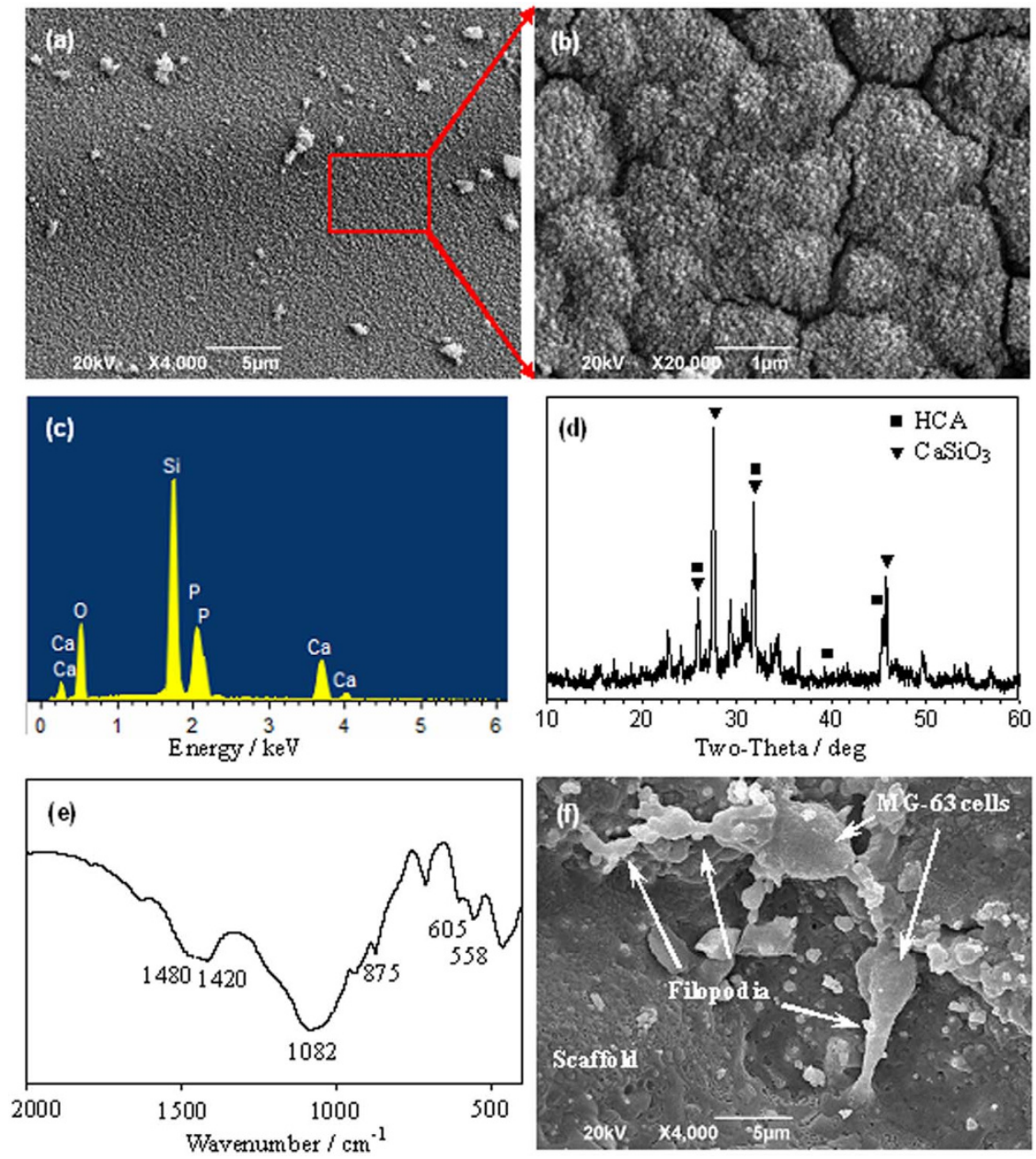

Figure 7 Biological tests. (a) Low magnification and (b) high magnification SEM images, (c) EDS spectrum, (d) XRD pattern and (e) FT-IR spectrum of 58S-0.5 after immersion in SBF for 7 days. (f) surface morphology of 58S-0.5 after cultured with MG-63 cells for 7 days. 

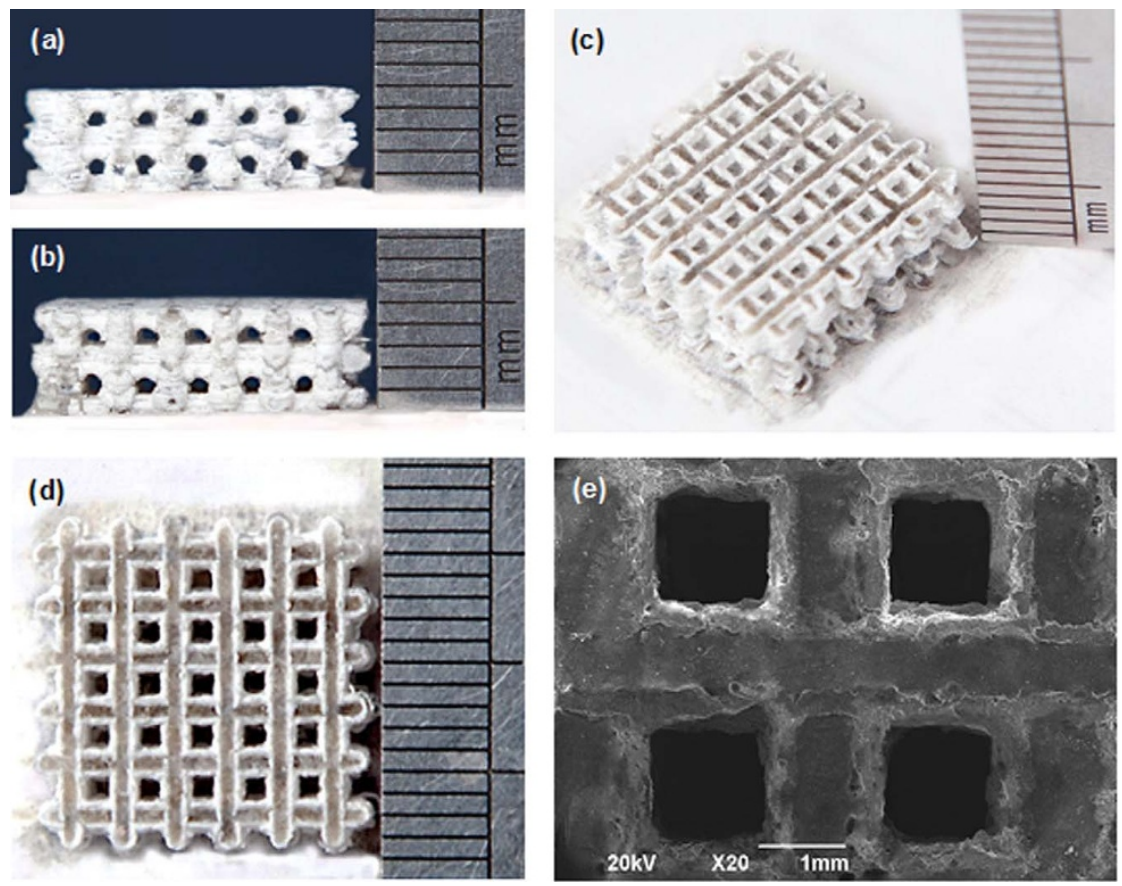

Figure $8 \mid$ Graphene/nano-58S composite scaffold by SLS. (a), (b) side views. (c) isometric view. (d) top view. (e) SEM image.
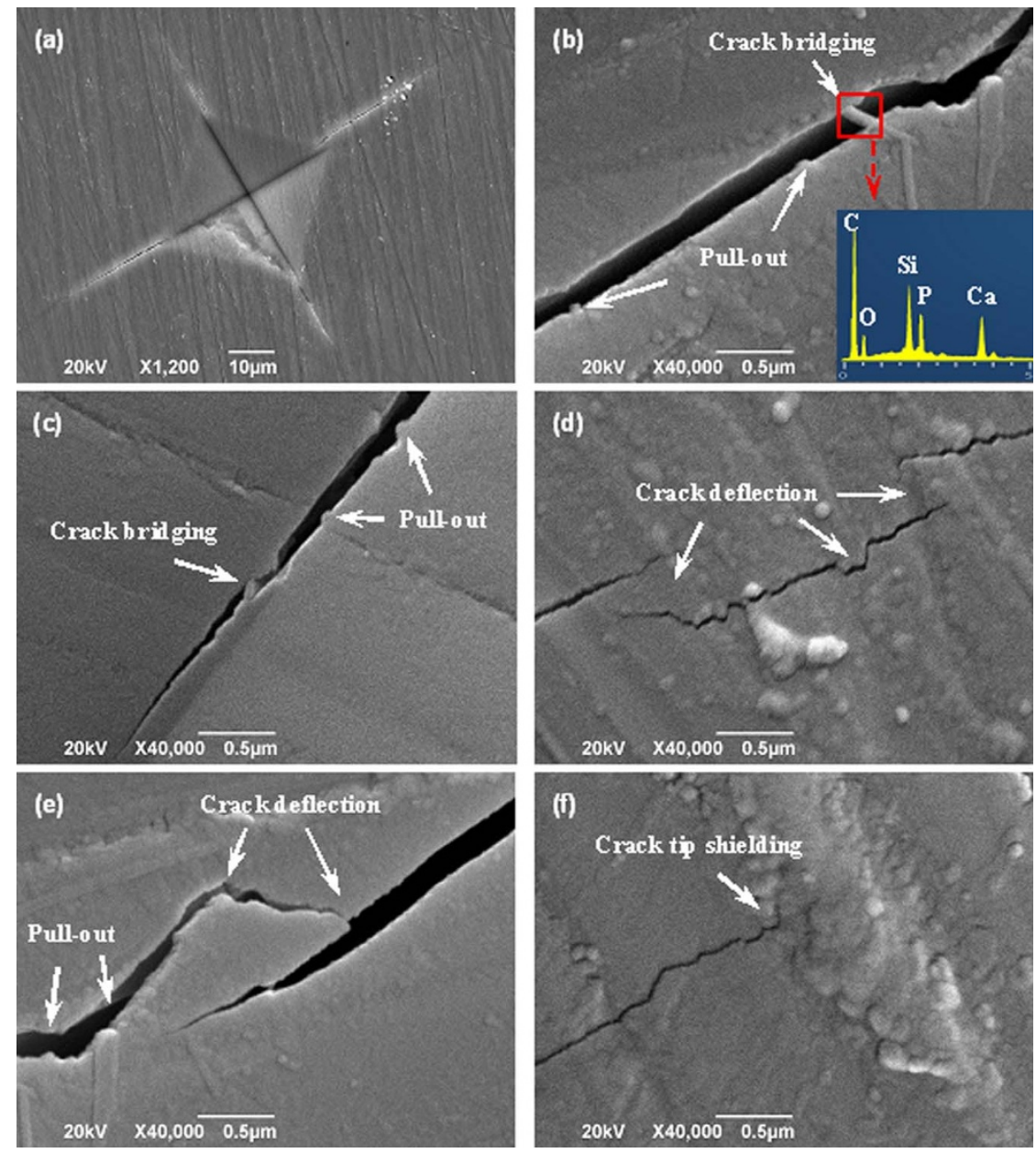

Figure 9 Inhibition of crack propagation by graphene in the sintered samples. SEM images of (a) microhardness indentation and radial cracks, (b-e) Crack deflection, crack bridging and graphene pull-out, (f) Termination of crack growth at the crack tip. 

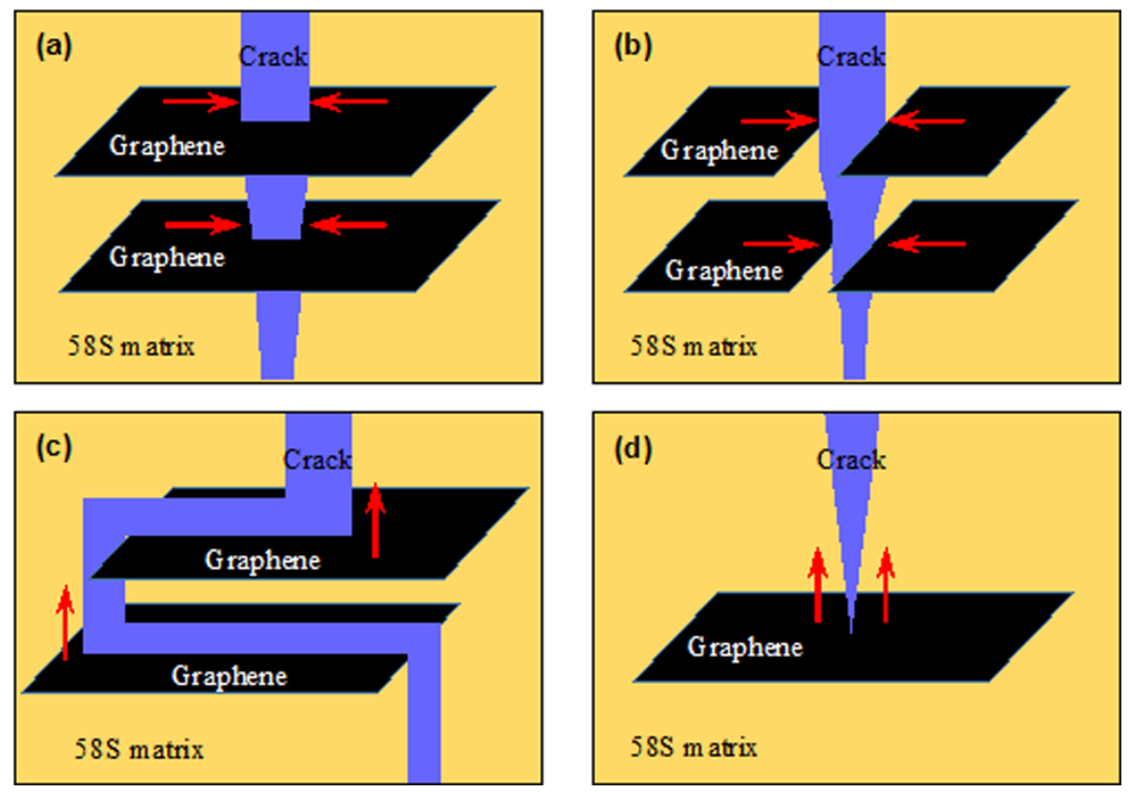

Figure $10 \mid$ A schematic of enhancement mechanisms in the sintered samples. (a) Crack bridging. (b) Graphene pull-out. (c) Crack deflection. (d) Crack tip shielding. The yellow region refers to $58 \mathrm{~S}$ matrix, black region refers to graphene, purple region refers to crack, and red arrow refers to the resistance to crack propagation by graphene.

in the vicinity of graphene due to the insufficient energy required for interface debonding. These mechanical enhancements get saturated with graphene content of $0.5 \mathrm{wt} \%$, as more graphene are difficult to disperse homogeneously in the nano-58S powder.

In summary, this study evaluates graphene as a potential reinforcement to nano-58S bone scaffold for enhancing the mechanical properties. Uniform dispersion of graphene, nano-58S and composite powders were obtained using NMP solvent. Graphene was successfully incorporated into the scaffold by SLS without obvious structural damage in spite of a slight increase of $\mathrm{I}_{\mathrm{D}} / \mathrm{I}_{\mathrm{G}}$ ratio. And there was little weight loss of graphene in the scaffold after the sintering process. The addition of graphene showed no influence on the phase composition of nano-58S scaffolds. The mechanical properties of nano-58S increased with the increase of graphene content $(0$ $0.5 \mathrm{wt} \%)$ and then diminished with graphene content of 1.0 or $1.5 \mathrm{wt} \%$. Incorporation of $0.5 \mathrm{wt} \%$ graphene improved the compressive strength of nano- $58 \mathrm{~S}$ by $105 \%$ and the fracture toughness by $38 \%$. Microstructural results demonstrated that pull-out, crack bridging, crack deflection and crack tip shielding were responsible for the mechanical enhancement. A well-formed HCA layer with $\mathrm{Ca} /$ $P$ ratio of 1.69 formed on the scaffold surface after immersing in SBF for 7 days. In vitro cell culture tests revealed that MG-63 cells colonized and grew favorably on the surface, suggesting a good cell biocompatibility of the composite scaffold. This study may pave the way for the mechanical enhancement of nano-58S scaffold in the application of bone tissue engineering.

\section{Methods}

Materials and experiments. Graphene (purity: $99.8 \%, 0.7-1.2 \mathrm{~nm}$ in thickness and $0.8-3 \mu \mathrm{m}$ in diameter) was purchased from Nanjing JCNANO Tech Co., Ltd. It was prepared by modified Hummers method ${ }^{46}$ with a metal impurity $<10$ PPM. $58 \mathrm{~S}$ bioactive glass was firstly prepared by sol-gel method. Then freeze-drying and grinding process were adopted to achieve nano-scale $58 \mathrm{~S}$ powder (average particle size of $48.3 \pm 6.6 \mathrm{~nm}$ ). N-methyl-2-pyrrolidone (NMP) (Tianjin Kemiou Chemical Reagent Co., Ltd., China) was used as the solvent for dispersing graphene due to the well matched surface energy to graphene ${ }^{47}$.

As-received graphene was firstly weighed using an electronic balance (Model FA1004, Changzhou Hengzheng Electronic Instrument Co., Ltd., China) and dispersed in NMP with concentration of $0.5 \mathrm{mg} / \mathrm{ml}$ using ultrasonic cleaning device (SK3300H, Shanghai Kudos Ultrasonic Instrument Co., Ltd., China) for $30 \mathrm{~min}$ Then, a certain amount of nano-58S powder was added to the solution and dispersed ultrasonically for another $30 \mathrm{~min}$. Subsequently, the resultant mixed solution was filtrated and dried by a rotary evaporator (RV 10 digital, IKA, Germany) at $60^{\circ} \mathrm{C}$ for $24 \mathrm{~h}$, followed by further drying in a vacuum oven (DZ-3, Tianjin Taisite Instrument Co., Ltd., China) for $24 \mathrm{~h}$ at $100^{\circ} \mathrm{C}$ to remove any trapped solvent. Finally, the composite powder was carefully peeled off the filter paper and broken up using pestle. By accurately weighing the graphene and nano- $58 \mathrm{~S}$ powder, the composite powders with different graphene contents ( $0 \mathrm{wt} \%, 0.1 \mathrm{wt} \%, 0.5 \mathrm{wt} \%, 1.0 \mathrm{wt} \%$ and $1.5 \mathrm{wt} \%)$ were obtained.

Experiments were carried out on a home-made SLS system in nitrogen atmosphere with laser power of $7.5 \mathrm{~W}$, scan speed of $100 \mathrm{~mm} / \mathrm{min}$, spot diameter of $1 \mathrm{~mm}^{48,49}$. And the sintered samples with different graphene contents were labeled as 58S-0, 58S-0.1, 58S-0.5, 58S-1 and 58S-1.5, respectively.

Microstructural characterization. The morphology of graphene, nano-58S and composite powder were observed with a field emission transmission electron microscope (JEM-2100F, JEOL Ltd., Japan) after the powders were ultrasonicated in NMP for 30 min to form homogeneous suspensions. The microstructure of sintered samples were characterized using a scanning electron microscope (JSM-6490LV, JEOL Ltd., Japan) at $20 \mathrm{kV}$ accelerating voltage after the samples were vacuum coated with platinum (JFC-1600 auto fine coater, JEOL Ltd., Japan). The element composition on the sample surface was studied using EDS (Neptune XM4, EDAX Inc., USA).

The phase analysis was conducted on a X-ray diffractometer (D/MAX 2550V, Rigaku, Japan) at $2 \theta$ range of $10-60^{\circ}$ using $\mathrm{CuK} \alpha$ radiation. FTIR spectra were recorded to identify the typical functional groups present in the samples using a Fourier transform infrared spectrometer (Nicolette TM 6700, Thermo Scientific Co., USA). The characterization was conducted with $\mathrm{KBr}$ pellets technique in a spectral region of $400-2000 \mathrm{~cm}^{-1}$. In order to determine the structure changes of graphene, Raman spectroscopic studies were performed on a LabRAM HR800 spectrometer (HORIBA Jobin Yvon, France) with laser wavelength of $488 \mathrm{~nm}$ and spot size of $0.1 \mathrm{~mm}$. TGA analysis was performed on a thermal analyzer (Netzsch STA 449C, Germany) to determine the weight retention with increasing temperature and further the amount of graphene in the samples. Prior to tests, all the samples were grinded to powders to ensure sufficient heat transfer. The measurements were conducted from ambient temperature to $750^{\circ} \mathrm{C}$ at a heating rate of $10^{\circ} \mathrm{C} / \mathrm{min}$ under air flow of $30 \mathrm{~mL} / \mathrm{min}$.

Mechanical properties assessment. Fracture toughness was determined by the indentation technique using a digital microhardness tester (HXD-1000TM/LCD, Shanghai Taiming Optical Instrument Co., Ltd., China). The samples were firstly inlayed by a mounting press (XQ-2B), followed by surface grinding with abrasive paper and polishing using diamond pastes. The indentations and cracks were made on the samples by loading to the maximum load (500 gf) in $10 \mathrm{~s}$, subsequently holding for $15 \mathrm{~s}$ and then unloading to zero load in $10 \mathrm{~s}$. The fracture toughness was calculated based on the crack length according to equation (1) ${ }^{50}$. A total of ten indentation data points were collected for each sample to check the reproducibility.

$$
K_{I C}=0.0824 \frac{P}{c^{3 / 2}}
$$


Where $P$ is the applied load $(\mathrm{N}), K_{I C}$ is the fracture toughness $\left(\mathrm{Pa} \cdot \mathrm{m}^{1 / 2}\right)$ and $c$ is the diagonal crack length $(\mathrm{m})$

Compression tests were performed on a universal testing machine (WD-D1, Shanghai Zhuoji instruments Co., Ltd., China) using an S-beam load cell at crosshead speed of $0.5 \mathrm{~mm} / \mathrm{min}$. Prior to the tests, samples were ground using abrasive papers $(400,600,800$ and 1000 -grit) under water lubrication. Subsequently, the surfaces were polished using successively finer grades of diamond paste to remove grinding damage. Ultrasonic cleaning was then applied to avoid any abrasive entrapment, followed by spraying the surfaces with alcohol and drying under a stream of hot air. The stress-strain curves were recorded and the compressive strengths were calculated from the maximum loads of stress-strain curves. For accuracy of results, ten data points were averaged for each group.

Biological properties assessment. The bioactivity of a scaffold is directly related to its ability to induce HCA formation. The HCA formation behavior of samples was evaluated in vitro by immersing them in SBF. The ion concentration $(\mathrm{mmol} / \mathrm{L})$ of $\mathrm{SBF}^{51}$ is similar to that of human plasma and presented as follows: $\mathrm{Na}^{+} 142.0, \mathrm{Ca}^{2+}$ $2.5, \mathrm{~K}^{+} 5.0, \mathrm{Mg}^{2+} 1.5, \mathrm{Cl}^{-} 147.8, \mathrm{HCO}_{3}{ }^{-} 4.2, \mathrm{HPO}_{4}{ }^{2-} 1.0$, and $\mathrm{SO}_{4}{ }^{2-} 0.5$. The samples were immersed in $\mathrm{SBF}(\mathrm{pH}=7.4)$ with a surface area $\left(\mathrm{cm}^{2}\right)$ to solution volume $(\mathrm{mL})$ ratio of $0.1 \mathrm{~cm}^{2} / \mathrm{mL}$ at $37^{\circ} \mathrm{C}$ for 7 days. The solution was renewed every 3 days to keep the ion concentration and $\mathrm{pH}$ constant for better simulation of the in vivo conditions. After immersing, the samples were extracted from the solution, gently rinsed with acetone, and dried at ambient temperature before further characterization.

Cell culture test was conducted to study the biocompatibility of scaffolds using MG-63 cells (American Type Culture Collection, Rockville, MD) isolated from human osteosarcoma. The cells were cultured in Dulbecco's modified Eagle's medium (DMEM, containing 10\% fetal bovine serum (FBS), $50 \mathrm{IU} / \mathrm{ml}$ penicillin and $50 \mathrm{mg} /$ $\mathrm{ml}$ streptomycin) under a humidified atmosphere of $5 \% \mathrm{CO}_{2}$ at $37^{\circ} \mathrm{C}$. The samples were firstly sterilized with ultraviolet radiation and preconditioned for $24 \mathrm{~h}$ in DMEM to prevent the sudden release of high ion concentrations from 58S. Then MG63 cells were seeded on the samples and incubated in 12-well cell culture plates for 7 days. The medium was changed every 3 days to guarantee a constant nutrition supply. After the cell culture, the samples were rinsed twice in phosphate buffered saline (PBS) and fixed with $2.5 \%$ glutaraldehyde. Dehydration was performed by sequential immersion in a graded series of ethanol solutions (70\%, $80 \%, 90 \%, 95 \%$ and $100 \%)$. Afterwards, the samples were dried and sputtered with platinum for SEM observations.

Statistical analysis. Data analysis was performed using SPSS 16.0 software (SPSS Inc., Chicago, IL, USA) and the data were expressed as mean \pm standard deviation (SD). Statistical analysis was conducted by two-tailed Student's t-tests between groups with different graphene contents $(\mathrm{n}=10)$. Differences were considered statistically significant when $p<0.05$

1. Labbaf, S. et al. Spherical bioactive glass particles and their interaction with human mesenchymal stem cells in vitro. Biomaterials 32, 1010-1018 (2011)

2. Roohani-Esfahani, S. I., Nouri-Khorasani, S., Lu, Z. F., Appleyard, R. C. \& Zreiqat, $\mathrm{H}$. Effects of bioactive glass nanoparticles on the mechanical and biological behavior of composite coated scaffolds. Acta Biomater. 7, 1307-1318 (2011).

3. Oudadesse, H., Gloriant, T., Fauré, J. \& Drevet, R. Electrophoretic Deposition of Bioactive Glass Coatings on Ti12Mo5Ta Alloy. Key Eng. Mater. 507, 135-140 (2012)

4. Gerhardt, L. C. et al. The pro-angiogenic properties of multi-functional bioactive glass composite scaffolds. Biomaterials 32, 4096-4108 (2011).

5. Hoppe, A., Güldal, N. S. \& Boccaccini, A. R. A review of the biological response to ionic dissolution products from bioactive glasses and glass-ceramics. Biomaterials 32, 2757-2774 (2011).

6. Misra, S. K. et al. Comparison of nanoscale and microscale bioactive glass on the properties of $\mathrm{P}(3 \mathrm{HB}) /$ Bioglass composites. Biomaterials 29, 1750-1761 (2008).

7. Ma, J., Chen, C. Z., Wang, D. G., Meng, X. G. \& Shi, J. Z. Influence of the sintering temperature on the structural feature and bioactivity of sol-gel derived $\mathrm{SiO}_{2}-$ $\mathrm{CaO}-\mathrm{P}_{2} \mathrm{O}_{5}$ bioglass. Ceram. Int. 36, 1911-1916 (2010).

8. O'Shea, T. M. \& Miao, X. Preparation and characterisation of plga-coated porous bioactive glass-ceramic scaffolds for subchondral bone tissue engineering. Ceram. Trans. 210, 517-523 (2010).

9. Boccaccini, A. R. et al. Polymer/bioactive glass nanocomposites for biomedical applications: A review. Compos. Sci. Technol. 70, 1764-1776 (2010).

10. Zhou, Y. L., Gao, Y. \& Chang, J. Effects of hydrolysis on dodecyl alcohol-modified bioactive glasses and PDLLA/modified bioactive glass composite films. J. Mater. Sci. 45, 6411-6416 (2010).

11. Liu, A. et al. Novel composites of poly(L-Lactide) and surface modified bioactive $\mathrm{SiO}_{2}-\mathrm{CaO}-\mathrm{P}_{2} \mathrm{O}_{5}$ gel nanoparticles: mechanical and biological properties. Chinese J. Polym. Sci. 27, 415-426 (2009).

12. Akhavan, O., Ghaderi, E. \& Akhavan, A. Size-dependent genotoxicity of graphene nanoplatelets in human stem cells. Biomaterials 33, 8017-8025 (2012).

13. Liang, J., Huang, Y., Zhang, L. \& Wang, Y. Molecular-level dispersion of graphene into poly (vinyl alcohol) and effective reinforcement of their nanocomposites. Adv. Funct. Mater. 19, 2297-2302 (2009).

14. Yang, K. et al. Graphene in mice: ultrahigh in vivo tumor uptake and efficient photothermal therapy. Nano Lett. 10, 3318-3323 (2010).
15. Sun, S., Gao, L. \& Liu, Y. Enhanced dye-sensitized solar cell using graphene- $\mathrm{TiO}_{2}$ photoanode prepared by heterogeneous coagulation. Appl. Phys. Lett. 96, 083113 (2010).

16. Melchels, F. P. W., Domingos, M. A. N. \& Klein, T. J. Additive manufacturing of tissues and organs. Prog. Polym. Sci. 37, 1079-1104 (2012).

17. Bai, P. \& Wang, W. Selective laser sintering mechanism of polymer-coated molybdenum powder. T. Nonferr. Metal. Soc. 17, 543-547 (2007).

18. Suárez-González, D. et al. Controllable mineral coatings on PCL scaffolds as carriers for growth factor release. Biomaterials 33, 713-721 (2012).

19. Kim, C. J., Khan, W., Kim, D. H., Cho, K. S. \& Park, S. Y. Graphene oxide/cellulose composite using NMMO monohydrate. Carbohyd. Polym. 86, 903-909 (2011).

20. Lu, J. et al. Self-supporting graphene hydrogel film as an experimental platform to evaluate the potential of graphene for bone regeneration. Adv. Funct. Mater. 23, 3494-3502 (2013).

21. Nayak, T. R. et al. Graphene for controlled and accelerated osteogenic differentiation of human mesenchymal stem cells. ACS nano 5, 4670-4678 (2011).

22. Zhou, G. et al. Graphene-wrapped $\mathrm{Fe}_{3} \mathrm{O}_{4}$ anode material with improved reversible capacity and cyclic stability for lithium ion batteries. Chem. Mater. 22, 5306-5313 (2010).

23. Kalita, G., Kayastha, M. S., Uchida, H., Wakita, K. \& Umeno, M. Direct growth of nanographene films by surface wave plasma chemical vapor deposition and their application in photovoltaic devices. RSC Adv. 2, 3225-3230 (2012).

24. Gollavelli, G. \& Ling, Y. C. Multi-functional graphene as an in vitro and in vivo imaging probe. Biomaterials 33, 2532-2545 (2012).

25. Guo, S. et al. Structurally controlled $\mathrm{ZnO} / \mathrm{TiO}_{2}$ heterostructures as efficient photocatalysts for hydrogen generation from water without noble metals: the role of microporous amorphous/crystalline composite structure. J. Power Sources $\mathbf{2 4 5}$, 979-985 (2013)

26. Patole, A. S. et al. A facile approach to the fabrication of graphene/polystyrene nanocomposite by in situ microemulsion polymerization. J. Colloid Interf. Sci. 350, 530-537 (2010).

27. Li, N. et al. Large scale synthesis of N-doped multi-layered graphene sheets by simple arc-discharge method. Carbon 48, 255-259 (2010).

28. Aguiar, H., Serra, J., González, P. \& León, B. Structural study of sol-gel silicate glasses by IR and Raman spectroscopies. J. Non-Cryst. Solids 355, 475-480 (2009).

29. He, Q. et al. Preparation, characterization and application of N-2Pyridylsuccinamic acid-functionalized halloysite nanotubes for solid-phase extraction of $\mathrm{Pb}$ (II). Water Res. 47, 3976-3983 (2013).

30. Groust, J. F., Costentin, G., Krafft, J. M. \& Massiani, P. Mechanism and deactivation process of the conversion of methylbutynol on basic faujasite monitored by operando DRIFTS. Phys. Chem. Chem. Phys. 12, 937-946 (2010).

31. Zhou, K., Zhu, Y., Yang, X., Jiang, X. \& Li, C. Preparation of graphene-TiO composites with enhanced photocatalytic activity. New J. Chem. 35, 353-359 (2011).

32. Gupta, A., Akhtar, A. J. \& Saha, S. K. In-situ growth of P3HT/graphene composites for supercapacitor application. Mater. Chem. Phys. 140, 616-621 (2013).

33. Choi, E. Y. et al. Noncovalent functionalization of graphene with end-functional polymers. J. Mater. Chem. 20, 1907-1912 (2010).

34. Wang, Y., Liu, J., Liu, L. \& Sun, D. D. High-quality reduced graphene oxidenanocrystalline platinum hybrid materials prepared by simultaneous coreduction of graphene oxide and chloroplatinic acid. Nanoscale Res. Lett. 6 , 241-248 (2011)

35. Mukherjee, D. P. \& Das, S. K. Effects of nano silica on synthesis and properties of glass ceramics in $\mathrm{SiO}_{2}-\mathrm{Al}_{2} \mathrm{O}_{3}-\mathrm{CaO}-\mathrm{CaF}_{2}$ glass system: A comparison. J. NonCryst. Solids 368, 98-104 (2013).

36. Hupfer, M., Zak, D., Roßberg, R., Herzog, C. \& Pöthig, R. Evaluation of a wellestablished sequential phosphorus fractionation technique for use in calcite-rich lake sediments: identification and prevention of artifacts due to apatite formation. Limnol. Oceanogr. Methods 7, 399-410 (2009).

37. Ma, B., Zhou, X., Bao, H., Li, X. \& Wang, G. Hierarchical composites of sulfonated graphene-supported vertically aligned polyaniline nanorods for highperformance supercapacitors. J. Power Sources 215, 36-42 (2012).

38. Manda, M. et al. The effect of high tempered firing cycle on the bioactive behavior of sol-gel derived dental porcelain modified by bioactive glass. J. Sol-Gel Sci. Techn. 63, 481-494 (2012).

39. Soong, Y., Goodman, A. L., McCarthy-Jones, J. R. \& Baltrus, J. P. Experimental and simulation studies on mineral trapping of $\mathrm{CO}_{2}$ with brine. Energy Convers. Manage. 45, 1845-1859 (2004)

40. Zhang, J. et al. Calcium phosphate/chitosan composite coating: Effect of different concentrations of $\mathrm{Mg}^{2+}$ in the m-SBF on its bioactivity. Appl. Surf. Sci. 280, 256-262 (2013)

41. Lei, B., Chen, X., Wang, Y. \& Zhao, N. Synthesis and in vitro bioactivity of novel mesoporous hollow bioactive glass microspheres. Mater. Lett. 63, 1719-1721 (2009).

42. Durdu, S., Deniz, Ö. F., Kutbay, I. \& Usta, M. Characterization and formation of hydroxyapatite on Ti6Al4V coated by plasma electrolytic oxidation. J. Alloys Compd. 551, 422-429 (2013).

43. Chen, X., Meng, Y., Wang, Y., Du, C. \& Yang, C. A biomimetic material with a high bio-responsibility for bone reconstruction and tissue engineering. J. Biomat. Sci-Polym. E 22, 153-163 (2011). 
44. Vaquette, C., Ivanovski, S., Hamlet, S. M. \& Hutmacher, D. W. Effect of culture conditions and calcium phosphate coating on ectopic bone formation. Biomaterials 34, 5538-5551 (2013).

45. Rafiee, M. A. et al. Fracture and fatigue in graphene nanocomposites. Small 6, 179-183 (2010).

46. Bong, S. et al. Graphene supported electrocatalysts for methanol oxidation. Electrochem. Commun. 12, 129-131 (2010).

47. Pham, V. H., Cuong, T. V., Hur, S. H., Oh, E. \& Kim, E. J. Chemical functionalization of graphene sheets by solvothermal reduction of a graphene oxide suspension in N-methyl-2-pyrrolidone. J. Mater. Chem. 21, 3371-3377 (2011).

48. Shuai, C. et al. Structure and properties of nano-hydroxypatite scaffolds for bone tissue engineering with a selective laser sintering system. Nanotechnology 22, 285703 (2011)

49. Shuai, C. et al. Structural design and experimental analysis of a selective laser sintering system with nano-hydroxyapatite powder. J. Biomed. Nanotechnol. 6 370-374 (2010).

50. Veljovic, D., Palcevskis, E., Zalite, I., Petrovic, R. \& Janackovic, D. Two-step microwave sintering-A promising technique for the processing of nanostructured bioceramics. Mater. Lett. 93, 251-253 (2013).

51. Leonor, I. B. et al. Alkaline treatments to render starch-based biodegradable polymers self-mineralizable. J. Tissue Eng. Regen. M. 1, 425-435 (2007).

\section{Acknowledgments}

This work was supported by the following funds: (1) The Natural Science Foundation of China (51222506, 81372366); (2) Hunan Provincial Natural Science Foundation of China;
(3) Program for New Century Excellent Talents in University (NCET-12-0544); (4) The Fundamental Research Funds for the Central Universities(2011JQ005, 2012QNZT015); (5) Project supported by the Fok Ying-Tong Education Foundation, China (131050); (6) Shenzhen Strategic Emerging Industrial Development Funds (JCYJ20130401160614372); (7) The Open-End Fund for the Valuable and Precision Instruments of Central South University; (8) Hunan Provincial Innovation Foundation For Postgraduate.

\section{Author contributions}

C.G. and C.S. conceived and designed the research. C.G., T.L. and S.P. performed experiments. C.G. and C.S. analyzed the data and wrote the manuscript. All authors reviewed the manuscript.

\section{Additional information}

Competing financial interests: The authors declare no competing financial interests.

How to cite this article: Gao, C.D., Liu, T.T., Shuai, C.J. \& Peng, S.P. Enhancement mechanisms of graphene in nano-58S bioactive glass scaffold: mechanical and biological performance. Sci. Rep. 4, 4712; DOI:10.1038/srep04712 (2014).

This work is licensed under a Creative Commons Attribution-NonCommercialShareAlike 3.0 Unported License. The images in this article are included in the article's Creative Commons license, unless indicated otherwise in the image credit; if the image is not included under the Creative Commons license, users will need to obtain permission from the license holder in order to reproduce the image. To view a copy of this license, visit http://creativecommons.org/licenses/by-nc-sa/3.0/ 